\title{
Fear of childbirth postpartum and its correlation with post-traumatic stress symptoms and quality of life among women with birth complications - a cross-sectional study
}

\author{
Hanna Grundström ${ }^{1,2} \mathbb{1} \cdot$ Anna Malmquist $^{3} \cdot$ Alice Ivarsson $^{2} \cdot$ Elin Torbjörnsson $^{2} \cdot$ Malin Walz $^{2} \cdot$ Katri Nieminen $^{1}$
}

Received: 2 July 2021 / Accepted: 22 February 2022 /Published online: 1 March 2022

(c) The Author(s) 2022

\begin{abstract}
The primary aim of the study was to analyze differences in post-traumatic stress symptoms (PTSS) and quality of life (QoL) between women with and without severe fear of childbirth postpartum (PP FOC). The secondary aims were to analyze the correlation between PP FOC and PTSS, and PP FOC and QoL, in women undergoing complicated childbirth. This crosssectional study was conducted in South-East Sweden. Women aged $\geq 18$ years who had undergone complicated childbirth (i.e., acute or emergency cesarean section, vacuum extraction, child in need of neonatal care, manual placenta removal, sphincter rupture, shoulder dystocia, or hemorrhage $\geq 1000 \mathrm{ml}$ ) were invited. Seventy-six women answered demographic questions and three validated instruments measuring PP FOC, PTSS, and QoL. The study population was divided into two sub groups: severe PP FOC or no severe PP FOC. Statistical analyses were conducted using Mann-Whitney $U$-test, chi-square test or Fisher's exact test, and Spearman's rank-order correlation. Severe PP FOC was reported by $29 \%$ of the women, and $18 \%$ reported PTSS indicating post-traumatic stress disorder. Women with severe PP FOC reported significantly higher levels of PTSS, and significantly lower QoL in five dimensions: physical role functioning, emotional role functioning, energy/ fatigue, emotional well-being, and social functioning. There was a positive significant correlation between level of PP FOC and PTSS. There were also significant negative correlations between level of PP FOC and most of the QoL dimensions. In conclusion, almost one-third of the women with complicated childbirth reported severe PP FOC, and almost one-fifth reported PTSS indicating post-traumatic stress disorder. PP FOC correlated with PTSS and deteriorated QoL.
\end{abstract}

Keywords Fear of childbirth · Quality of life · Post-traumatic stress symptoms · PTSS · Complicated childbirth $\cdot$ PTSD

\section{Introduction}

Becoming a mother is a profound life event that affects women's lives on several levels: socially, emotionally, mentally, and physiologically. For many women, it is the most intense emotional transition in life (Halldorsdottir and Karlsdottir 1996; Martins 2019). The first 6 weeks after childbirth is

Hanna Grundström

hanna.grundstrom@liu.se

1 Department of Obstetrics and Gynecology in Norrköping, and Department of Biomedical and Clinical Sciences, Linköping University, Linköping, Sweden

2 Department of Health, Medicine and Caring Sciences, Linköping University, Linköping, Sweden

3 Department of Behavioral Sciences and Learning, Linköping University, Linköping, Sweden a critical period where the adaptation to motherhood and recovery is established (Henshaw et al. 2018). A positive birth experience is related to positive effects on postpartum health, and can help women to adapt to the role of motherhood (Dahlberg and Aune 2013). For most women, the transition to motherhood is uncomplicated, but around one of three reports feeling down, depressed or hopeless, or having less interest or pleasure in daily routines (Declercq et al. 2014). Complications related to childbirth increase the risk of postpartum mental ill-health and for developing fear of childbirth postpartum (PP FOC) (Størksen et al. 2013).

FOC can be experienced on a continuum and varies from almost no fear to phobic fear. In clinical practice, the severity of FOC can be divided into four categories: low, moderate, severe, and phobic. Severe FOC interferes with the women's personal lives including emotional, social, and working aspects, and can influence their willingness to become pregnant again (American Psychiatric Association 2002; Wijma 
and Wijma 2017). FOC during pregnancy also increases the risk of experiencing the childbirth as traumatic and stressful (Ayers 2004).

Up to $30 \%$ of women perceive their childbirth as threatening or traumatizing during the initial period after childbirth (Ayers 2004), and some women develop post-traumatic stress disorder (PTSD) due to traumatic childbirth experiences. A range of 1-6\% suffers from PTSD during the period of 1 to 6 months postpartum (Ayers 2004; Söderquist et al. 2009; Yildiz et al. 2017). Furthermore, $10 \%$ of women experience post-traumatic stress symptoms (PTSS) but do not fulfil all the diagnostic criteria for PTSD (Ayers 2004).

Complications during or after childbirth seem to have a negative effect on women's rating of their QoL postpartum (Van der Woude et al. 2015). Maternal healthcare for women and their families before, during, and after childbirth has the potential to affect the occurrence of complications, women's birth experiences, and the risk for developing PP FOC (Ayers 2014; Larsson et al. 2015). Therefore, it is important to analyze prevalence and correlations among PP FOC, low QoL, and risk factors for PTSD postpartum to gain more knowledge on how to develop and implement health-promoting protocols (Martínez-Galiano et al. 2019). The primary aim of the study was to analyze differences in PTSS and QoL between women with and without severe PP FOC. The secondary aims were to analyze the correlations between PP FOC and PTSS, and PP FOC and QoL, in women undergoing complicated childbirth.

\section{Materials and methods}

\section{Design}

This is a cross-sectional study conducted in a population with high risk for postpartum FOC. It was performed at a hospital in a middle sized city in South-East Sweden with around 2300 births per year. The study is a part of a larger project testing the effect of a postpartum support program based on psychological first aid. In this study, we used the collected data in a cross-sectional design.

\section{Sampling and data collection}

Inclusion criteria to participate in the study were women aged $\geq 18$ years having undergone complicated childbirth during the past 1 to 3 months. Complications were defined as acute or emergency cesarean section, vacuum extraction, child in need of neonatal care, manual placenta removal, sphincter rupture, shoulder dystocia, or hemorrhage $\geq 1000 \mathrm{ml}$ (Johnson and Slade 2003; World Health Organization 2018). Exclusion criteria were not able to read and speak Swedish, diagnosis of bipolar or psychotic disease, or suicidality. The women's clinical data (age, parity, date of giving birth, and type of birth complication) were collected from the medical records together with their postal addresses for sending out the survey.

Consecutive sampling was performed, where 157 eligible women were invited to participate. They were invited from September 2019 to August 2020 and had given birth 1 to 3 months earlier. An information letter was sent with a prepaid reply envelope, a research questionnaire with demographic questions, and three validated instruments measuring PP FOC (the Wijma Delivery Expectancy/Experience Questionnaire version B (W-DEQ B)), PTSS (Impact of Event Scale-Revised (IES-R)), and QoL (Short Form Health Survey-36 (SF-36)). By answering the questionnaire and returning their responses, 76 women gave their informed consent to participate.

\section{Instruments}

\section{The Wijma Delivery Expectancy/Experience Questionnaire version $B$}

W-DEQ B is a validated and standardized instrument to measure PP FOC in a 33-item scale. In W-DEQ B, women assess statements related to the childbirth on a 0-5 Likert scale, ranging from "not at all" $(=0)$ to "extremely" $(=5)$. A W-DEQ B-sum score of $\geq 85$ indicates severe PP FOC, which is often also the FOC level with a clinical impact on the woman's well-being (Wijma et al. 1998).

\section{Impact of Event Scale-Revised}

IES-R is a validated screening instrument to measure the level of PTSS, experienced by the person in the last 7 days related to a specific event, in this case childbirth (Weiss and Marmar 1997; Sundin and Horowitz 2002). IES-R contains 22 items with propositions intended to cover PTSS, where women assess each proposition on a 0-4 Likert scale, ranging from "not at all" $(=0)$ to "extremely" $(=4)$. After the IES-R questionnaire is filled out, the sum score is calculated (range 0-88). Sum scores $\geq 33$ are considered to indicate PTSD (Creamer et al. 2003).

\section{Short Form Health Survey-36}

SF-36 is a validated and reliable instrument to measure general psychological health and QoL. SF-36 consists of 36 items which are grouped into 8 dimensions focusing on different aspects of QoL. A specific algorithm is used to calculate the dimension sum scores, ranging from 0 (low QoL) to 100 (high QoL) (Sullivan et al. 1995). 


\section{Statistical analysis}

Data were analyzed using IBM SPSS 26.0. The study population was divided into two sub groups according to W-DEQ B sum score: severe PP FOC (W-DEQ sum score $\geq 85$ ) or no severe PP FOC (W-DEQ sum score $<85$ ). Variables on continuous scales were described as median, 25th and 75th percentiles, and nominal data as frequency and percentage. For missing answers, mean imputation of existing values was performed. Comparison of demographic and clinical characteristics and questionnaire data was conducted using Mann-Whitney $U$-test for continuous data and chi-square test or Fisher's exact test for nominal data. The correlation analyses were conducted on the entire study population as one group. Spearman's rank-order correlation was used to measure the strength and direction of the relations between PP FOC (sum score) and PTSS (IES-R sum score), and PP FOC (sum score) and QoL (score of each dimension), respectively. Spearman's rho correlation coefficient and the $p$-value were presented. To allow comparison with earlier studies using parametric tests, mean and standard deviations were also reported. The level of statistical significance was set at $p<0.05$.

\section{Results}

Seventy-six women participated in the study, of whom 22 women reported severe PP FOC (29\%). There were no significant differences in the demographic and clinical characteristics between the two study groups. Women's median age was 32 years. The majority of the women were cohabiting with the child's other parent. Most of the women had no previous or current diseases. The most common complication was vacuum extraction followed by acute cesarean section (Table 1).

As shown in Table 2, 14 women in the whole population scored $\geq 33$ on IES-R, resulting in an $18 \%$ prevalence of PTSS on a level indicating PTSD. The median sum score of IES-R was 16 (mean 23) for women with severe PP FOC, and median 9 (mean 14), for women without severe PP FOC, which was a significantly lower score $(p=0.009)$.

Concerning women's self-reported QoL, there was a statistically significant difference between women with and without severe PP FOC in five dimensions: those with severe PP FOC scored significantly lower in physical role functioning ( $p=0.045)$, emotional role functioning $(p \leq 0.001)$, energy/fatigue ( $p=0.008)$, emotional well-being $(p=0.003)$, and social functioning $(p=0.006)$ (Table 2).

Correlation analyses were conducted in the entire study to examine the correlations between level of PP FOC and PTSS, and between PP FOC and the dimensions of QoL (Table 3 ). There was a positive significant correlation (correlation coefficient 0.547 ) between level of PP FOC and PTSS $(p \leq 0.001)$, i.e., the higher PP FOC, the more PTSS.

There were also significant correlations between level of PP FOC and some of the QoL dimensions: emotional role functioning (correlation coefficient -0.438 , $p \leq 0.001$ ), energy/fatigue (correlation coefficient -0.296 , $p=0.009$ ), emotional well-being (correlation coefficient $-0.412, p \leq 0.001$ ), social functioning (correlation coefficient $-0.362, p=0.001$ ), pain (correlation coefficient $-0.229 p=0.047$ ), and general health (correlation coefficient $-0.310 p=0.006$ ). The negative correlation coefficients indicate that higher PP FOC is correlated with lower QoL.

\section{Discussion}

Our results show that women with severe PP FOC express higher levels of PTSS and report lower QoL. There was a significant correlation between level of PP FOC and PTSS and between level of PP FOC and the QoL dimensions concerning emotional role functioning, energy/fatigue, emotional well-being, social functioning, pain, and general health.

In this study, all women had undergone a complicated childbirth, which is a known risk factor for PP FOC, PTSD, and deteriorated QoL postpartum, which may explain the high levels of PP FOC and PTSS in our population (Ayers 2004; Størksen et al. 2013; Van der Woude et al. 2015). As expected, the women in our study had a higher prevalence of PP FOC (29\%) compared with results from a systematic review of studies including general international postpartum populations, where 6-15\% were diagnosed with severe PP FOC (Nilsson et al. 2018).

Almost one-fifth, 18\%, scored over the cut-off for PTSS indicating PTSD. This can be compared with $10 \%$ reporting stress symptoms and 1-6\% diagnosed with PTSD in the general postpartum population (Ayers 2004; Söderquist et al. 2009; Yildiz et al. 2017). Furthermore, women in this study reported a deteriorated QoL in all subscales except for physical functioning and general health compared with a normal population of adult Swedish women (Sullivan et al. 2002).

Our results show a significant correlation between PP FOC and higher level of PTSS which is in line with research highlighting FOC as a strong predictive factor for PTSD postpartum. This in turn is correlated with a more negative birthing experience, and negative impact on the health of the new family and the start of life of the baby. PP FOC also increases the risk for psychological illness later in life (Söderquist et al. 2006).

Our results highlight the necessity for maternal healthcare to follow up and to support women with increased 
Table 1 Demographic and clinical characteristics of women with and without severe fear of childbirth postpartum and of the total sample

\begin{tabular}{|c|c|c|c|}
\hline & $\begin{array}{l}\text { Severe } \\
\text { PP FOC } \\
(n=22)\end{array}$ & $\begin{array}{l}\text { No severe PP } \\
\text { FOC }(n=54)\end{array}$ & Total sample $(n=76)$ \\
\hline Age median (25th percentile-75th percentile) & $32(29-35)$ & $31(29-35)$ & $32(29-35)$ \\
\hline \multicolumn{4}{|l|}{ Parity $n(\%)$} \\
\hline First child & $17(77)$ & $35(65)$ & $52(68)$ \\
\hline Second child or more & $5(23)$ & $19(35)$ & $24(32)$ \\
\hline \multicolumn{4}{|l|}{ Civil status" $n(\%)$} \\
\hline No partner & $1(5)$ & $2(4)$ & $3(4)$ \\
\hline Has a partner but not cohabiting & $3(14)$ & $1(2)$ & $4(5)$ \\
\hline Married or cohabiting & $18(82)$ & $51(94)$ & $69(91)$ \\
\hline \multicolumn{4}{|l|}{ Education ${ }^{*} n(\%)$} \\
\hline Mandatory school & & $2(4)$ & $2(3)$ \\
\hline High school & $7(32)$ & $16(30)$ & $23(30)$ \\
\hline University & $15(68)$ & $36(67)$ & $51(67)$ \\
\hline \multicolumn{4}{|l|}{ Employment before childbirth $^{*} n(\%)$} \\
\hline Working full-time & $15(68)$ & $40(74)$ & $55(72)$ \\
\hline Working part-time & $1(5)$ & $5(9)$ & $6(8)$ \\
\hline Student & $4(18)$ & $5(9)$ & $8(11)$ \\
\hline Sick leave & $1(5)$ & $1(2)$ & $2(3)$ \\
\hline Parental leave & & $2(4)$ & $2(3)$ \\
\hline Other & $1(5)$ & $1(2)$ & $2(3)$ \\
\hline \multicolumn{4}{|l|}{ Previous diseases $^{*+} n(\%)$} \\
\hline No previous diseases & $15(68)$ & $39(72)$ & $54(71)$ \\
\hline Psychiatric illness, i.e., depression, GAD, or anxiety & $1(5)$ & $6(11)$ & $7(9)$ \\
\hline Other previous diseases & $7(32)$ & $9(17)$ & $16(21)$ \\
\hline \multicolumn{4}{|l|}{ Current diseases $^{+*} n(\%)$} \\
\hline No current diseases & $15(68)$ & $42(78)$ & $57(75)$ \\
\hline Psychiatric illness, i.e., depression, GAD, or anxiety & $2(9)$ & $4(7)$ & $6(8)$ \\
\hline Other current diseases & $6(27)$ & $7(13)$ & $13(17)$ \\
\hline \multicolumn{4}{|c|}{ Counselling with midwife specialized on FOC during pregnancy ${ }^{+*} n(\%)$} \\
\hline Yes & $6(27)$ & $13(24)$ & $19(25)$ \\
\hline No & $16(73)$ & $41(76)$ & $57(75)$ \\
\hline \multicolumn{4}{|l|}{ Complications at birth $^{+} n(\%)$} \\
\hline Vacuum extraction & $8(36)$ & $18(33)$ & $26(34)$ \\
\hline Acute cesarean section & $6(27)$ & $14(26)$ & $20(26)$ \\
\hline Hemorrhage $\geq 1000 \mathrm{ml}$ & $3(14)$ & $9(17)$ & $12(16)$ \\
\hline Sphincter rupture & $2(9)$ & $7(13)$ & $9(12)$ \\
\hline Child in need of neonatal care & $2(9)$ & $5(9)$ & $7(9)$ \\
\hline Manual placenta removal & $1(5)$ & $5(9)$ & $6(8)$ \\
\hline Emergency cesarean section & $3(14)$ & $2(4)$ & $5(7)$ \\
\hline Shoulder dystocia & & $3(6)$ & $3(4)$ \\
\hline
\end{tabular}

No significant differences were found between the study groups. $S D$, standard deviation; $G A D$, generalized anxiety disorder; PP FOC, severe fear of childbirth postpartum. ${ }^{+}$Some women gave multiple answers. *Self-reported answers risk for PP FOC, such as complicated births or negative childbirth experiences. It also urges the need of interventions to improve postpartum care and to support the natural recovery after a complicated or traumatic childbirth in order to prevent PP FOC and PTSS. Postpartum care in relation to birthing experiences has been under investigation both internationally (Simpson and Catling 2016; Hollander et al. 2017) and in Sweden (Barimani et al. 2015), and there is room for improvement in fulfilling women's needs of emotional support and the quality of personal interactions postpartum (Barimani et al. 2015; Simpson and Catling 2016; Hollander et al. 2017; National Board of Health and Welfare 
Table 2 Reported levels of post-traumatic stress symptoms and quality of life 1 to 3 months postpartum. Comparison between women with and without severe fear of childbirth postpartum

\begin{tabular}{|c|c|c|c|c|}
\hline & & Severe PP FOC $(n=22)$ & $\begin{array}{l}\text { No severe PP } \\
\text { FOC }(n=54)\end{array}$ & $p$-value \\
\hline \multicolumn{5}{|c|}{ Post-traumatic stress symptoms (IES-R) } \\
\hline \multirow[t]{2}{*}{ Sum score $\geq 33$} & Yes $n(\%)$ & $6(27)$ & $8(15)$ & n.s \\
\hline & No $n(\%)$ & $16(73)$ & $46(85)$ & \\
\hline \multicolumn{2}{|c|}{ Median (25th percentile-75th percentile) } & $16(10-38)$ & $9(3-19)$ & 0.009 \\
\hline \multicolumn{2}{|l|}{ Mean \pm SD } & $23 \pm 19$ & $14 \pm 15$ & \\
\hline \multicolumn{5}{|l|}{ Quality of life (SF-36) } \\
\hline \multicolumn{5}{|c|}{ Median (25th percentile-75th percentile) } \\
\hline \multicolumn{2}{|l|}{ Physical functioning } & $90(74-96)$ & $90(75-95)$ & n.s \\
\hline \multicolumn{2}{|l|}{ Role functioning/physical } & $63(0-100)$ & $100(50-100)$ & 0.045 \\
\hline \multicolumn{2}{|l|}{ Role functioning/emotional } & $33(0-100)$ & $100(67-100)$ & $<0.001$ \\
\hline \multicolumn{2}{|l|}{ Energy/fatigue } & $33(14-54)$ & $55(40-70)$ & 0.008 \\
\hline \multicolumn{2}{|l|}{ Emotional well-being } & $56(43-78)$ & $78(64-89)$ & 0.003 \\
\hline \multicolumn{2}{|l|}{ Social functioning } & $63(38-100)$ & $100(63-100)$ & 0.006 \\
\hline \multicolumn{2}{|l|}{ Pain } & $56(29-88)$ & $68(49-84)$ & n.s \\
\hline \multicolumn{2}{|l|}{ General health } & $75(67-88)$ & $82(74-92)$ & n.s \\
\hline \multicolumn{5}{|l|}{ Mean \pm SD } \\
\hline \multicolumn{2}{|l|}{ Physical functioning } & $84 \pm 19$ & $83 \pm 21$ & \\
\hline \multicolumn{2}{|l|}{ Role functioning/physical } & $49 \pm 47$ & $71 \pm 38$ & \\
\hline \multicolumn{2}{|l|}{ Role functioning/emotional } & $42 \pm 44$ & $83 \pm 32$ & \\
\hline \multicolumn{2}{|l|}{ Energy/fatigue } & $37 \pm 25$ & $54 \pm 22$ & \\
\hline \multicolumn{2}{|l|}{ Emotional well-being } & $60 \pm 20$ & $75 \pm 17$ & \\
\hline \multicolumn{2}{|l|}{ Social functioning } & $63 \pm 32$ & $83 \pm 20$ & \\
\hline \multicolumn{2}{|l|}{ Pain } & $55 \pm 34$ & $67 \pm 24$ & \\
\hline \multicolumn{2}{|l|}{ General health } & $72 \pm 22$ & $80 \pm 16$ & \\
\hline
\end{tabular}

$n . s$, not significant; IES-R, Impact of Event Scale-Revised; SF-36, Short Form Health Survey-36; PP FOC, severe fear of childbirth postpartum
Table 3 Correlations between postpartum fear of childbirth and posttraumatic stress symptoms, and between fear of childbirth postpartum and dimensions of quality of life

\begin{tabular}{lcc}
\hline & $\begin{array}{l}\text { Correlation } \\
\text { coefficient }\end{array}$ & $p$-value \\
\hline $\begin{array}{l}\text { Post-traumatic stress symptoms* } \\
\text { Dimensions of quality of life (SF-36)** }\end{array}$ & 0.547 & $<0.001$ \\
Physical functioning & & n.s \\
Role functioning/physical & & n.s \\
Role functioning/emotional & -0.438 & $<0.001$ \\
Energy/fatigue & -0.296 & 0.009 \\
Emotional well-being & -0.412 & $<0.001$ \\
Social functioning & -0.362 & 0.001 \\
Pain & -0.229 & 0.047 \\
General health & -0.310 & 0.006 \\
\hline
\end{tabular}

n.s, not significant. *Sum score of IES-R (Impact of Event ScaleRevised). **Sum score of dimensions of SF-36 (Short Form Health Survey-36)

2017). Almost half of the mothers in a Swedish study perceived that the received support from maternal healthcare during the first 2 weeks postpartum was insufficient and lacking in emotional support (Barimani et al. 2015). According to the Swedish National Board of Health and Welfare, postpartum care mostly focuses on the child's well-being in combination with the somatic and physical health of the mother. Only 16 of 43 Swedish hospitals (37\%) have written routines in order to identify and manage mental illness among women who recently experienced a childbirth. Thus, the Swedish National Board of Health and Welfare highlights the need to increase preventative and continual emotional support postpartum (National Board of Health and Welfare 2017). One way to identify women in need of additional emotional support could be a follow-up screening for those with higher risk of PP FOC.

Our study showed a significant correlation between PP FOC and mainly the emotional and social aspects of QoL. Women with severe PP FOC also scored significantly lower in those aspects of QoL compared with women without severe PP FOC. There is limited research on correlations between FOC and QoL. In a recent study of Malawian postnatal women, high levels of PP FOC were negatively related to QoL (Khwepeya et al. 2020). Furthermore, childbirth-related concerns during pregnancy may decrease QoL (Kazemi et al. 2017), as might high levels of postpartum 
symptoms of anxiety and depression (Gulseren et al. 2018). It has also been suggested that the transition to motherhood itself indicates profound changes in life, where the physical, social, and emotional changes may have a substantial negative impact on women's QoL (Martins 2019; Emmanuel and St John 2010). Additionally, the women in this study have undergone a complicated childbirth, and together with high PP FOC and a high level of PTSS, the decrease in QoL is understandable. However, with that being said, this further highlights the necessity of improved postpartum care, including interventions to prevent PP FOC and PTSS, to prevent decreased QoL, and to facilitate natural emotional recovery after childbirth.

The relatively small sample size and the low response rate are limitations of the study. Despite the small sample, the differences between the groups (PP FOC/no PP FOC) and the correlations between PP FOC and PTSS/QoL were significant using non-parametric tests. Furthermore, the scores on IES-R should be interpreted with caution as it is a screening test, and the psychiatrist conducted interview is the gold standard for diagnosis of PTSD (American Psychiatric Association 2002). We have no information on the ethnic background of the participants, which in turn may limit the generalizability of the study.

To the best of our knowledge, it is the first study to examine the prevalence of PP FOC in a risk group and its correlations with PTSS and QoL during the vulnerable period of transition to motherhood. Our conclusions highlight the importance of supporting women with FOC already during pregnancy and to raise awareness of the risk of mental health problems after complicated childbirth. Maternal healthcare has contact with the women throughout pregnancy and birth and thus has the opportunity to prevent complications, identify individuals at risk, and facilitate the natural psychological recovery of women affected by PP FOC.

\section{Conclusion}

Complicated birth is a distressing experience: almost onethird of the women reported severe PP FOC, and almost every fifth woman reported PTSS indicating PTSD. Severe PP FOC correlated both with PTSS and deteriorated QoL postpartum. More studies of QoL are needed as well as studies of treatment of PP FOC and PTSS following birth.

\footnotetext{
Author contribution Hanna Grundström, Anna Malmquist, and Katri Nieminen contributed to the study conception and design. Material preparation and data collection were performed by Hanna Grundström, and analyses were performed by Alice Ivarsson, Elin Torbjörnsson, and Malin Walz. The first draft of the manuscript was written by Hanna Grundström and all authors commented on previous versions of the manuscript. All authors read and approved the final manuscript.
}

Funding Open access funding provided by Linköping University. This study was funded by Region Östergötland and Linköping University.

Availability of data and material Data on request.

Code availability Not applicable.

\section{Declarations}

Ethics approval This study was performed in line with the principles of the Declaration of Helsinki. It was approved by the Swedish Ethical Review Authority 2019-11-28 (Reg. no. 2019-04820).

Consent to participate Informed consent was obtained from all participants included in the study.

Consent for publication Consent for data publication was obtained from all participants included in the study.

Conflict of interest The authors declare no competing interests.

Open Access This article is licensed under a Creative Commons Attribution 4.0 International License, which permits use, sharing, adaptation, distribution and reproduction in any medium or format, as long as you give appropriate credit to the original author(s) and the source, provide a link to the Creative Commons licence, and indicate if changes were made. The images or other third party material in this article are included in the article's Creative Commons licence, unless indicated otherwise in a credit line to the material. If material is not included in the article's Creative Commons licence and your intended use is not permitted by statutory regulation or exceeds the permitted use, you will need to obtain permission directly from the copyright holder. To view a copy of this licence, visit http://creativecommons.org/licenses/by/4.0/.

\section{References}

American Psychiatric Association (2002) Quick reference to the diagnostic criteria from DSM-IV-TR. Pilgrim Press, Malmö

Ayers S (2004) Delivery as a traumatic event: prevalence, risk factors, and treatment for postnatal posttraumatic stress disorder. Clin Obstet Gynecol 47(3):552-567. https://doi.org/10.1097/01.grf. $0000129919.00756 .9 \mathrm{c}$

Ayers S (2014) Fear of childbirth, postnatal post-traumatic stress disorder and midwifery care. Midwifery 30(2):145-148. https://doi. org/10.1016/j.midw.2013.12.001

Barimani M, Oxelmark L, Johansson S-E, Hylander I (2015) Support and continuity during the first 2 weeks postpartum. Scand J Caring Sci 29(3):409-417. https://doi.org/10.1111/scs.12144

Creamer M, Bell R, Falilla S (2003) Psychometric properties of the Impact of Event Scale Revised. Behav Res Ther 41:1489-1496. https://doi.org/10.1016/j.brat.2003.07.010

Dahlberg U, Aune I (2013) The woman's birth experience-the effect of interpersonal relationships and continuity of care. Midwifery 29(4):407-415. https://doi.org/10.1016/j.midw.2012.09.006

Declercq E, Sakala C, Corry M, Applebaum S, Herrlich A (2014) Major survey findings of listening to mothers(SM) III: new mothers speak out: report of national surveys of women's childbearing eexperiences. J Perinat Educ 23(1):17-24. https://doi.org/10.1891/ 1058-1243.23.1.17 
Emmanuel E, St John W (2010) Maternal distress: a concept analysis. J Adv Nurs 66(9):2104-2115. https://doi.org/10.1111/j.1365-2648. 2010.05371.x

Gulseren D, Dilek B, Özkan SA (2018) Depression, anxiety and quality of life of mothers in the early postpartum period. Int J Behav Sci 11:152-159

Halldorsdottir S, Karlsdottir SI (1996) Journeying through labour and delivery: perceptions of women who have given birth. Midwifery 12(2):48-61. https://doi.org/10.1016/s02666138(96)90002-9

Henshaw E, Cooper M, Jaramillo M, Lamp J, Jones A, Wood T (2018) "Trying to figure out if you're doing things right, and where to get the info": parents recall information and support needed during the first 6 weeks postpartum. Matern Child Health J 22(11):16681675. https://doi.org/10.1007/s10995-018-2565-3

Hollander MH, van Hastenberg E, van Dillen J, van Pampus MG, de Miranda E (2017) Stramrood C (2017) Preventing traumatic childbirth experiences: 2192 women's perceptions and views. Arch Womens Ment Health 20(4):515-523. https://doi.org/10.1007/ s00737-017-0729-6

Johnson RC, Slade P (2003) Obstetric complications and anxiety during pregnancy: is there a relationship? J Psychosom Obstet Gynecol 24(1):1-14. https://doi.org/10.3109/01674820309042796

Kazemi F, Nahidi F, Kariman N (2017) Exploring factors behind pregnant women's quality of life in Iran: a qualitative study. Electron Physician 9(12):5991-6001. https://doi.org/10.19082/5991

Khwepeya M, Monsen K, Kuo S-Y (2020) Quality of life and the related factors in early postnatal women in Malawi. Midwifery 85:102700. https://doi.org/10.1016/j.midw.2020.102700

Larsson B, Karlström A, Rubertsson C, Hildingsson I (2015) The effects of counseling on fear of childbirth. Acta Obstet Gynecol Scand 94(6):629-636. https://doi.org/10.1111/aogs.12634

Martinez-Galiano J, Hernández-Martínez A, Rodríguez-Almagro J, Delgado-Rodríguez M, Rubio-Alvarez A, Gómez-Salgado J (2019) Women's quality of life at 6 weeks postpartum: influence of the discomfort present in the puerperium. Int J Environ Res Public Health 16:253. https://doi.org/10.3390/ijerph16020253

Martins C (2019) Transition to parenthood: consequences on health and well-being. A qualitative study. Enferm Clin 29(4):225-233. https://doi.org/10.1016/j.enfcli.2018.04.005

National Board of Health and Welfare (2017) Care after childbirth—a national survey of postpartum care (In Swedish). https://www. socialstyrelsen.se/globalassets/sharepointdokument/artikelkat alog/ovrigt/2017-413.pdf Accessed July 12021

Nilsson C, Hessman E, Sjöblom H, Dencker A, Jangsten E, Mollberg M, Patel H, Sparud Lundin C, Wigert H, Begley C (2018) Definitions, measurements and prevalence of fear of childbirth: a systematic review. BMC Preg Childb 18(1):28. https://doi.org/10. 1186/s12884-018-1659-7

Simpson M, Catling C (2016) Understanding psychological traumatic birth experiences: a literature review. Women Birth 29(3):203207. https://doi.org/10.1016/j.wombi.2015.10.009
Størksen H, Garthus-Niegel S, Vangen S, Eberhard-Gran M (2013) The impact of previous birth experiences on maternal fear of childbirth. Acta Obstet Gynecol Scand 92(3):318-324. https://doi.org/ 10.1111/aogs. 12072

Sullivan M, Karlsson J, Ware J (1995) The Swedish SF-36 Health Survey I. Evaluation of data quality, scaling assumptions populations, reliability and construct validity across general populations in Sweden. Soc Sci Med 41:1349-1358. https://doi.org/10.1016/ 0277-9536(95)00125-q

Sullivan M, Karlsson J, Taft C (2002) SF-36 Hälsoenkät: Svensk Manual och Tolkningsguide. (In Swedish) Sahlgrenska universitetssjukhuset:Göteborg, Sweden

Sundin E, Horowitz M (2002) Impact of Event Scale: psychometric properties. Br J Psychiatry 180:205-209. https://doi.org/10.1192/ bjp.180.3.205

Söderquist J, Wijma B, Wijma K (2006) The longitudinal course of post-traumatic stress after childbirth. J Psychosom Obstet Gynaecol 27(2):113-119. https://doi.org/10.1080/01674820600712172

Söderquist J, Wijma B, Thorbert G, Wijma K (2009) Risk factors in pregnancy for post traumatic stress and depression after childbirth. BJOG 116(5):672-680. https://doi.org/10.1111/j.1471-0528.2008. 02083.x

Van der Woude D, Pijnenborg J, de Vries J (2015) Health status and quality of life in postpartum women: a systematic review of associated factors. Eur J Obstet Gynecol Reprod Biol 185:45-52. https://doi.org/10.1016/j.ejogrb.2014.11.041

Weiss DS, Marmar CR (1997) The Impact of Event Scale-Revised. In: Wilson JP, Keane TM (eds) Assessing psychological trauma and PTSD. Guilford, New York, pp 399-411

Wijma K, Wijma B (2017) A woman afraid to deliver: how to manage childbirth anxiety. In: Bio-psycho social obstetrics and gynecology. Springer International Publishing, Switzerland

Wijma K, Wijma B, Zar M (1998) Psychometric aspects of the W-DEQ; a new questionnaire for the measurement of fear of childbirth. $J$ Psychosom Obstet Gynaecol 19(2):84-97. https://doi.org/10.3109/ 01674829809048501

World Health Organization (2018) Definition of skilled health personnel providing care during childbirth. WHO/RHR/18.14. https:// apps.who.int/iris/bitstream/handle/10665/272817/9789241514 200-eng.pdf. Accessed 2020-02-06

Yildiz PD, Ayers S, Phillips L (2017) The prevalence of posttraumatic stress disorder in pregnancy and after birth: a systematic review and meta-analysis. J Affect Disord 15(208):634-645. https://doi. org/10.1016/j.jad.2016.10.009

Publisher's note Springer Nature remains neutral with regard to jurisdictional claims in published maps and institutional affiliations. 